\title{
Accountability: uma revisão sistemática da produção do EnANPAD e EnAPG
}

\section{Accountability: a systematic review of the production of EnANPAD and EnAPG}

Nathanni Marrelli Matos Mauricio', Tatyane Alves das Neves Mendes

Rodrigues², Suzana Gilioli da Costa Nunes ${ }^{3}$

\section{RESUMO}

O objetivo deste artigo é descrever a contribuição do EnANPAD e do EnAPG para a produção de conhecimento sobre a accountability. Para isso, foi realizada uma revisão sistemática nos anais desses eventos referentes ao período de 1997 a 2016, com a análise de 50 artigos. Percebeu-se que há uma manutenção do número de trabalhos sobre a temática; que 69 autores são responsáveis pelos 50 artigos analisados; 14 autores participaram da elaboração de mais de um trabalho; sendo que os portais governamentais e os Tribunais de Contas foram os objetos mais estudados; o termo "controle" foi o elemento mais citado nos conceitos de accountability, seguido dos termos "Prestação de Contas", "Transparência" e "Responsabilidade"; e com relação às dimensões (tipologias) de accountability constatou-se que a mais citada foi a "accountability vertical" e a "accountability horizontal" de O'Donnell (1998).

Palavras-chave: Accountability. Controle. Transparência.

\section{ABSTRACT}

The purpose of this article is to describe the contribution of EnANPAD and EnAPG to the production of knowledge about accountability. For this, a systematic review was performed in the annals of these events referring to the period from 1997 to 2016, with the analysis of 50 articles. It was noticed that there is a maintenance of the number of works on the subject; that 69 authors are responsible for the 50 articles analyzed; 14 authors participated in the elaboration of more than one work; being that the governmental portals and the Courts of Accounts were the most studied objects; the term "control" was the most cited element in the concepts of accountability, followed by the terms "Accountability", "Transparency" and "Accountability"; and with respect to the dimensions (typologies) of accountability it was verified that the most cited was O'Donnell's (1998) "vertical accountability" and "horizontal accountability".

Keywords: Accountability. Control. Transparency.
1 Mestre em Gestão de Políticas Públicas pela UFT, Especialista em Gestão Pública pela FAEL, Graduada em Administração pela UFT. Administradora da Universidade Federal do Tocantins

.E-mail: nathanni@uft.edu.br

${ }^{2}$ Aluna do Mestrado Profissional de Administração Pública

Profiap UFT. Especialização em Docência do Ensino Superior pela Faculdade ITOP / Centro Avançado de Ensino ITOP, Técnico-Administrativo de Nível Superior da Fundação Universidade Federal do Tocantins.

E-mail: tatyneves@uft.edu.br

3 Pós doutora pela UNESP, Mestre em Gestão da Qualidade pela Unicamp, especialista em Administração Financeira e Docência do Ensino Superior, graduada em Administração pela PUC de Goiás, professora adjunto do curso de Administração da Universidade Federal do Tocantins.

E-mail: suzanagilioli@uft.edu.br 


\section{INTRODUÇÄAO}

Atualmente, para o aperfeiçoamento da gestão pública, é preciso avançar na transparência e divulgação das informações sobre o gerenciamento da máquina estatal, envolver os cidadãos na discussão e tomada de decisões sobre as políticas públicas e desenvolver mecanismos mais rigorosos de acompanhamento na implementação das decisões deliberadas (NASCIMENTO; TEODÓSIO, 2015). Assim, cresce a necessidade e a cobrança por parte da sociedade de mecanismos que promovam transparência, responsabilização, controle, participação, prestação de contas, dentre outros (DUARTE et al., 2016). Todos esses aspectos estão ligados direta ou indiretamente ao conceito de accountability.

Nesse contexto, o termo accountability tem se expandido de forma significativa na esfera da administração pública, dentre os inúmeros argumentos que demostram sua importância se destacam três como justificativas para esse estudo: contribui para redução da má alocação dos recursos públicos e da corrupção; contribui para melhorar o sistema de governança do país; e é um alicerce para a efetiva democracia.

Rocha et al. (2012) destacam que a demanda por accountability se origina da opacidade do poder. São comuns notícias de fraudes, enriquecimentos ilícitos, superfaturamento, desvios de verbas, suborno e outros meios de apropriação indevida do dinheiro público por pessoas e entes privados (LIMA; CAMPOS, 2010). Mas, se por um lado surgiram novas oportunidades para a prática corrupta, por outro fomentou pressões por accountability, que, segundo Juaninha e Peixe (2016), promove práticas de eficiência governamental e iniciativas de mitigação e combate à corrupção no setor público. Silveira e Silveira (2006) corroboram afirmando que a accountability trabalha como uma intimidação e um desincentivo para as práticas corruptas.

Além disso, a accountability é um elemento importante e característico de boa governança do setor público, segundo o TCU, os princípios da boa governança são: legitimidade, equidade, responsabilidade, eficiência, probidade, transparência e accountability (TCU, 2014).

Em suma, a existência de mecanismos de accountability contribuem para a melhoria da gestão pública, permitem a identificação de práticas lesivas ao patrimônio público e viabilizam a responsabilização dos seus autores, impedindo que a impunidade se concretize e desencorajando a perpetração de ações semelhantes pelos seus demais agentes (SACRAMENTO; PINHO, 2015). 
Além dos três argumentos supracitados, que enaltecem a importância dos estudos sobre a accountability, percebe-se que as pesquisas sobre o tema utilizam conceitos diferentes, em função do que se estuda e se apropriam de diversas dimensões conceituais para delimitar o campo de análise da accountability (XAVIER; 2011).

Dessa forma, o objetivo deste artigo é descrever a contribuição dos encontros da Associação Nacional de Pós-Graduação e Pesquisa em Administração (EnANPAD) e dos encontros de Administração Pública e Governança da Associação Nacional de PósGraduação e Pesquisa em Administração (EnAPG) para a produção de conhecimento sobre a accountability. Para isso, propõe-se: analisar a distribuição temporal dos artigos publicados no período de 1997 a 2016; verificar a participação dos autores por meio da descrição da quantidade de autores que publicaram sobre o tema, quantidade de artigos por autor e quantidade de autores que escreveram o artigo; identificar o objeto principal pesquisado nos artigos; elencar os elementos utilizados no conceito de accountability; e enumerar as classificações das dimensões (tipologias) de accountability.

\section{REVISAOO BIBLIOGRÁFICA}

\subsection{Conceito de Accountability}

O termo accountability não apresenta tradução literal para o português e não há como identificar apenas uma única palavra que resuma o conceito, mas se pode ter uma ideia de seu significado. Muitos autores concordam que não há um consenso sobre o sentido de accountability, pois as distintas abordagens apontam diferentes significados, sendo tratada na literatura de forma abrangente e variada (LIMA; CAMPOS, 2010; ROCHA, 2010; ROCHA et al., 2012; ZAPELINI, 2012; VIEIRA; PEREIRA, 2013; MORAIS, 2014; DUARTE; BORRELLI; ZOUAIN, 2016), por isso acabou se tornando um termo multifacetado, de múltiplas dimensões, carregado de significados e aplicabilidades.

Várias publicações têm buscado um termo que melhor traduza a accountability para a língua portuguesa, assim as definições encontradas na literatura tendem a variar acentuadamente não apenas de autor para autor, mas também conforme a disciplina no qual o trabalho se insere.

O termo accountability deriva do latim e é composto por ad+computare, que significa "contar para, prestar contas a, dar satisfação a, corresponder à expectativa de" (ZAPELINI, 2012). 
De acordo com Nascimento e Teodósio (2015), a palavra accountability remete à habilidade de algo ou alguém ser accountable a outro por alguma coisa, ou seja, ser responsável por suas decisões ou ações, e, ainda, estar disponível para dar explicações sobre elas quando solicitado.

É inegável que a accountability não se resume à questão legal ou à prestação formal de contas, mas vai além, tendo forte relação com a participação da sociedade. Nesse contexto, Martins e Tavares (2015) afirmam que muito mais que a prestação de contas em si, a accountability se refere à habilidade dos cidadãos de influenciar na transparência de seus líderes, governantes e instituições públicas. Ceneviva e Farah (2012) corroboram destacando que a transparência e a visibilidade das ações governamentais são peças-chave para a accountability.

Ribeiro, Campelo e Araújo (2005) apontam a concepção de accountability na administração pública atinente ao pressuposto da "transparência" na aplicação de recursos públicos; e há casos onde o termo é traduzido por "responsabilidade" (ZAPELINI, 2012). Enquanto Rezende, Silva e Santos (2015), para resumir o conceito de accountability, apontam especificamente para os elementos: transparência, participação e prestação de contas.

Segundo Rocha (2007) a accountability pode ser entendida como a permanente responsabilização dos gestores públicos quanto a avaliação da conformidade e legalidade, da economia, da eficiência, da eficácia e da efetividade dos atos praticados em decorrência do uso do poder que a sociedade outorga para eles. Em linhas gerais, para Louzada, Fontes e Rezende (2010) o conceito de accountability está ligado ao dever que um representante eleito tem de prestar contas àqueles que representam, bem como as formas como esses representantes são cobrados e responsabilizados.

Para Pó (2005), a accountability é um conceito que inclui a existência de condições para os cidadãos participarem da definição e avaliação das políticas públicas, premiando ou punindo os responsáveis, por isso deve haver disponibilidade de informações sobre a atuação dos governos e seus resultados, bem como instituições que permitam contestar as ações do Poder Público.

De acordo com Nascimento e Teodósio (2015), a razão da existência da accountability está na necessidade de exercer controle sobre o poder público, assim, a accountability pode ser compreendida como uma relação entre cidadãos e governantes, na qual ambas as partes atuam para responder e corresponder às demandas de 
promoção do bem público, contribuindo para um avanço democrático e para o aprimoramento da gestão pública.

O`Donnell (1998) destaca dois aspectos principais da accountability: a obrigação do governante e do funcionário de sujeitar seus atos à lei; e a obrigação do governante de prestar contas dos seus atos, com suficiente transparência para que a cidadania possa avaliar sua gestão e, mediante procedimentos democráticos, ratificá-la ou rechaçá-la.

Borges (2014) destaca que accountability representa algo similar à reponsabilidade objetiva ou obrigação de responder por algo. O conceito de accountability é sintetizado por Pinho e Sacramento (2009) como a obrigação e a responsabilização de quem ocupa um cargo a prestar contas com base na lei, estando envolvida a possibilidade de ônus, caso não seja cumprido essa diretiva. Sano e Abrucio (2003) afirmam que a obrigatoriedade é inerente a accountability e todo agente público deve ter ciência dessa obrigação, mas, caso isso não ocorra, ela deverá ser exigida da sociedade.

Loureiro e Abrucio (2003, p.1) definem accountability como "a construção de mecanismos institucionais pelos quais os governantes são constrangidos a responder, ininterruptamente, por seus atos ou omissões perante os governados". Em outras palavras, é saber o que os agentes públicos estão fazendo, como estão fazendo, que consequências resultam das suas ações e como estão sendo responsabilizados (ROCHA, 2009).

Cabe ressaltar que a accountability não se limita à prestação de contas pelo administrador público por meio dos instrumentos tradicionais de controle, nem tão pouco é a simples substituição desses controles pela fiscalização direta da sociedade. Accountability é, na realidade, a integração de todos os meios de controle (formais e informais) aliada a uma superexposição da administração, que passa a exibir suas contas ao exame dos fiscais, diariamente, por meio de demonstrativos que contribuem para ampliar o número de controladores (SANTOS; SILVA; MORAIS, 2016).

Borges (2014) destaca que, em regimes democráticos, o desenvolvimento de formas e instrumentos de accountability é uma das atividades sociais mais importantes e consiste em criar processos de avaliação e responsabilização permanente dos agentes públicos.

Sacramento e Pinho (2012) definem a estrutura conceitual da accountability a partir de três elementos: informações, justificações e sanções. A informação e a justificação remetem à dimensão que os autores denominam de answerability, ou seja, a capacidade de respostas dos governos, a obrigação dos oficiais públicos de informarem e explicarem 
seus atos; já a punição diz respeito à capacidade de enforcement, ou seja, a capacidade das agências de impor sanções e perda de poder para aqueles que violarem os deveres públicos.

De acordo com Silveira e Silveira (2006, p. 2), "accountability implica manifestar expectativas sobre os resultados a alcançar; monitorar e informar publicamente os progressos; usar informações para melhoria da performance; e trabalhar para alcançar resultados e vincular responsabilidades aos mesmos". Os autores ressaltam que podem existir relações de accountability entre os governantes e o eleitorado; entre os políticos e o serviço público; entre os gerentes e seus assessores; e entre os financiadores de serviços, fornecedores e seus clientes.

Koppell (2005) apresenta cinco dimensões para análise e para discussão de práticas de accountability: transparência referente ao modo de mostrar a atuação das organizações e dos agentes públicos; imputabilidade que se refere ao fato de que as organizações e indivíduos devem ser responsabilizados pelas suas ações e punidos pelos malefícios que vierem a causar; controle que está relacionado às relações hierárquicas no interior das estruturas burocráticas, seja entre indivíduos ou organizações; responsabilização que diz respeito ao cumprimento das leis, das normas e das regras estabelecidas e às sanções decorrentes de seu descumprimento; e responsividade que se refere ao modo como a organização responde às expectativas da sociedade.

É perceptível que os conceitos listados nessa seção possuem muitos elementos em comum, por isso, com vistas a facilitar o entendimento do termo, um dos objetivos dessa pesquisa foi sintetizar os elementos que constituem o conceito de accountability segundo os autores dos artigos analisados.

\subsection{Classificação Dimensões (tipologias) de Accountability}

$\mathrm{Na}$ literatura pesquisada, verifica-se que diversos estudiosos têm empreendido esforços para classificar a accountability. Neste sentido, tipologias têm sido apresentadas na tentativa de explicar o conceito e delimitar o estudo. Neste tópico, com base em levantamento efetuado, algumas dessas tipologias são apresentadas e discutidas. Para Xavier (2011), os estudiosos do tema não somente utilizam conceitos diferenciados em função do foco dado ao estudo, como também se apropriam de dimensões para conceituar e delimitar o estudo. 
A classificação de O'Donnell (1998) é considerada uma das principais referências na literatura que versa sobre a accountability e o autor é o pioneiro na distinção e conceituação das suas diferentes formas. Com a utilização de uma metáfora espacial que tem por finalidade descrever as relações de poder, o autor estabelece uma diferenciação entre accountability vertical e accountability horizontal.

Segundo Xavier (2011), nesta tipologia, a verticalidade é usada para mostrar uma relação hierárquica, em que no topo se encontra o detentor de poder, e, na base, quem delega o poder. Em suma, a acountability vertical descreve uma relação entre desiguais, entre superiores e subordinados, entre principais e agentes. $O$ autor da tipologia, O'Donnell (1998, p. 28), define accountability vertical como "ações realizadas individualmente ou por algum tipo de ação organizada e/ou coletiva, com referência àqueles que ocupam posições em instituições do Estado, eleitos ou não".

A eleição é a forma mais conhecida de accountability vertical, além disso, diz respeito, também, à participação da sociedade civil, reinvindicações sociais e atuação da imprensa na comunicação de massa dessas reivindicações e de atos supostamente ilícitos praticados por autoridades públicas (XAVIER, 2011; VIEIRA; PEREIRA, 2013; MARTINS; TAVARES, 2015; SANTOS; MORAIS, 2016). Ressalta-se que para que esta dimensão possa realmente funcionar "é preciso que haja ampla informação sobre o que fazem os agentes públicos, que as preferências sejam reconhecidas e bem estabelecidas e que haja boa dose de pluralismo" (XAVIER, 2011, p.6), além disso, a dimensão vertical assegura a democracia numa ordem política (MARTINS; TAVARES, 2015).

De acordo com Sacramento (2015), a accountability vertical é a dimensão de atuação dos cidadãos comuns e das organizações da sociedade civil, enquanto a accountability horizontal é a dimensão da relação de entes estatais. Corroborando com essa afirmação, Xavier (2011) destaca que na accountability vertical um agente sem poder legal pode punir ou premiar um agente com poder político, enquanto na accountability horizontal são os agentes públicos que se controlam mutuamente.

O'Donnell (1998) conceitua a accountability horizontal como aquela que se efetiva mediante a mútua fiscalização entre os poderes (checks and balances), através de agências estatais que possuem o direito e o poder legal de controlar a atividade pública, realizando ações que vão desde a supervisão de rotina até sanção legal contra ações ou emissões de outros agentes ou agências do Estado que possam ser qualificadas como delituosas. 
Os mecanismos de accountability horizontal incluem as instituições clássicas do Executivo, Legislativo e Judiciário; as agências de supervisão, como os ombudsmen; as instâncias de fiscalização e prestação das contas (MARTINS; TAVARES, 2015). Para que a accountability horizontal seja efetiva, segundo Zapelini (2012), é necessária a existência de agências públicas que possuam competência legal, autonomia política e capacidade para supervisionar, controlar e punir ações julgadas ilícitas realizadas por outros agentes públicos.

Xavier (2011) destaca a importância da mobilização da sociedade e da mídia para que os agentes públicos que possuem competência legal para supervisionar tomem as ações necessárias, assim, a accountability vertical que surge por meio das reivindicações sociais com forte apoio da mídia é capaz de provocar um impacto na accountability horizontal.

Mainwaring (2003) e Schmitter (2007) também utilizam uma metáfora espacial para a classificação da accountability, mas ampliam as relações de poder que não estão incluídas nem no tipo vertical e nem no horizontal.

Mainwaring (2003) utiliza a denominação accountability intraestado para se referir à relação entre agências de Estado, sendo que a principal diferença com relação à accountability horizontal é que a segunda se limita às violações legais, enquanto a primeira considera também possíveis violações políticas dentro do seu conceito de accountability. Xavier (2011) exemplifica a accountability intraestado com o que acontece em governos parlamentares, com a queda do gabinete em função de processo baseado em questões estritamente políticas.

Schmitter (2007) conceitua a accountability oblíqua, que é um complemento da accountability vertical, e pode ser de grande importância na informação e no apoio às agências de Estado envolvidas na ativação da accountability horizontal. Este tipo de accountability se refere à relação de cobrança exercida pelas diversas organizações da sociedade civil que não indicam candidatos e nem participam das eleições, mas que são capazes de mobilizar cidadãos para defender seus interesses no processo político, assim, essa ação coletiva acontece continuamente, mesmo fora do período eleitoral, e tem como foco todos os espaços políticos onde são decididas a alocação de recursos públicos.

Smulovitz e Peruzzotti (2003) apresentam a accountability societal, que é um mecanismo vertical de controle das autoridades públicas exercido por associações de cidadãos e por movimentos da mídia, podendo empregar tanto mecanismos institucionais, 
como, por exemplo, o Ministério Público, como mecanismos não institucionais, como mobilizações sociais.

De acordo com Quiñones, Herrera \& Hernandes (2011), além da accountability vertical e horizontal, há a accountability transversal (social ou societal) que trata de iniciativas nas quais o controle seria realizado pela sociedade civil através de espaços políticos institucionais estatais, podendo ser conduzido tanto por atores coletivos, que seriam concebidos como representantes da sociedade civil em conselhos e comitês que monitoram as políticas públicas, quanto diretamente por cidadãos individuais.

No modelo de classificação elaborado por Xavier (2014), há duas dimensões: Constitucional (accountability como mecanismo social) e Organizacional (accountability como virtude). E cada uma dessas dimensões se desmembra em três tipos de accountability.

Na dimensão constitucional, a accountability é vista como mecanismo social e visa a estabelecer a atuação das funções de cada elemento do desenho organizacional, de modo a dificultar a concentração de poder, sendo classificada em: legal, horizontal e de reputação. A accountability legal refere-se ao cumprimento ou não das normas legais, ao conjunto de mecanismos que asseguram que as ações dos agentes públicos estejam legal e constitucionalmente enquadradas; na accountability horizontal os diferentes entes do poder público controlam uns aos outros, visando a evitar a concentração de poder e possível abuso de conduta; e a accountability de reputação envolve, de alguma forma, a participação das auditorias dos órgãos governamentais (XAVIER, 2014).

$\mathrm{Na}$ dimensão organizacional, há uma preocupação com a obtenção de resultados desejáveis para a sociedade, relaciona-se com a boa governança e como atingi-la. Nesse contexto, a accountability é classificada como: de transparência, de participação e de resultados. A accountability de transparência se refere às práticas que orientam a publicidade de informações; a accountability de participação é a formalização de políticas para compartilhar os processos de decisão com as partes interessadas; e a accountability de avaliação se refere à sustentação dos princípios de boa prática e aos procedimentos de disseminação das lições aprendidas (XAVIER, 2014).

Outro tipo de classificação presente na literatura é a apresentada por Romzek (1996), que diferenciam quatro tipos "primários" de accountability, usando como critérios o grau e a fonte do controle dos relacionamentos. Para os autores, a accountability pode ser classificada como: hierárquica; legal; política; profissional. 
A accountability hierárquica é caracterizada pelo elevado grau de controle, exercido a partir de uma fonte interna, baseada na supervisão, portanto com baixa autonomia, onde se enfatizam as expectativas dos supervisores e gestores no topo da hierarquia organizacional em relação aos funcionários (ROMZEK; INGRAHAM, 2000). Podem-se citar como exemplo desse tipo de accountability as regras, regulamentos e diretrizes.

A accountability legal é baseada na fiscalização externa (auditorias) e estruturas legislativas, o grau de controle é elevado, e as principais expectativas dizem respeito ao cumprimento da lei e obrigações contratuais (ROMZEK; 1996).

A accountability política reflete a ênfase na orientação de serviço ao cliente e capacidade de resposta às suas necessidades, os gestores têm o poder de decidir se e como responder às preocupações das partes interessadas, assim, há baixo grau de controle, exercido por fonte interna (ROMZEK; INGRAHAM, 2000).

A accountability profissional trata-se do tipo que enfatiza a responsabilidade acima de tudo, alto grau de discricionariedade, pois há baixo grau de controle e este é exercido basicamente por fontes externas, os relacionamentos de accountability se baseiam na capacidade e expertise profissional dos administradores públicos, e a confiança é essencial para garantir esse relacionamento (ROMZEK; INGRAHAM, 2000).

Grant e Keohane (2005) identificam sete tipos de mecanismos de accountability, separando em dois grupos: no primeiro estão aqueles que dependem fortemente de delegação (accountability hierárquico, supervisão, fiscal e legal); e no segundo grupo os mecanismos que de alguma forma envolvem a participação (accountability de mercado, pelos pares e de reputação). A accountability hierárquica se aplica às relações superiorsubordinado existentes dentro das organizações; a accountability de supervisão é utilizada nas relações que envolvem organizações, onde uma organização atua como principal em relação à outra; a accountability fiscal envolve a responsabilização de recursos financeiros; a accountability legal se refere à exigência de que os agentes públicos respeitem as regras e estejam preparados para justificar suas ações em tribunais; a accountability de mercado procura mostrar a influência que os investidores e os consumidores exercem no mercado, quando escolhem ou não investir em um determinado país em função de divergências políticas, ou quando um consumidor se recusa a comprar produtos de uma empresa que utiliza, por exemplo, madeira florestal de área desmatada; a accountability dos pares surge com o resultado da avaliação mútua das organizações que possuem finalidades semelhantes; a accountability de reputação pública é apresentada como um mecanismo que está envolvido em todas as outras 
formas de accountability, sendo aplicada a situações em que a reputação ampla e publicamente conhecida fornece meios para que de alguma forma se possa avaliar determinada situação.

De acordo com Denhardt e Denhardt (2003), a accountability assume determinadas características quando vista à luz dos modelos de administração pública: a accountability de processos conforme o modelo clássico ou da Administração Pública Tradicional; a accountability de resultados no modelo da Nova Gestão Pública; e a accountability democrática de acordo com o modelo do Novo Serviço Público. A accountability de processos está relacionada em conformidade com as leis e as normas procedimentais; a accountability de resultados é representada pela obtenção da máxima produtividade dos recursos públicos mediante o controle dos resultados da ação, com base nos conceitos de eficiência e eficácia/efetividade; accountability democrática é multifacetada e baseada na responsividade do agente público, na qual sobressaem as questões relativas ao desempenho responsável, à postura ética, à defesa do interesse público e à ação comprometida com os princípios democráticos.

\section{MATERIAIS E METODOS}

O artigo foi desenvolvido por meio de uma revisão sistemática dos anais do EnANPAD e do EnAPG que estão entre os mais importantes fóruns de discussão sobre a produção acadêmica em Administração e, especificamente, na Administração Pública no Brasil. Ressalta-se que o EnAPG surgiu, a partir da 27ª edição do EnANPAD, em 2003, e é realizado de dois em dois anos.

A coleta de dados ocorreu mediante consulta no site da associação por meio da palavra accountability, na busca avançada, marcando os eventos de interesse, com vistas a encontrar os artigos que possuíam o termo no título, ou seja, que tratavam do tema accountability como questão principal. O recorte temporal foi de trabalhos publicados entre os anos de 1997 a 2016.

Após, realizou-se um filtro dos artigos, com a leitura dos resumos, sendo escolhidos os trabalhos que discutiam a accountability no âmbito da Administração Pública. Foram encontrados 35 artigos no Enanpad, e 17 no EnAPG, mas dois artigos do primeiro evento não tratavam do tema no âmbito da Administração Pública, assim, foram analisados 50 artigos.

Os artigos selecionados foram analisados com a finalidade de descrever os seguintes aspectos: distribuição temporal dos artigos; verificar a participação dos autores; 
identificar os objetos de pesquisa; enumerar os elementos utilizados para conceituar a accountability e suas dimensões (tipologias).

Para Roesch (2005), ao encerrar a coleta de dados, o pesquisador se depara com uma quantidade de informações as quais terá de organizar para depois interpretar. Foi realizada análise temática, seguindo a regra da homogeneidade de Bardin (2016). As palavras-chave foram identificadas quanto à aparição e agrupadas de acordo com a semelhança, principalmente para analisar os elementos considerados nos conceitos de accountability e as abordagens (tipologias) da accountability.

Utilizou-se o seguinte roteiro de procedimentos para a análise dos dados qualitativos (GIL, 2006): leitura com atenção dos textos que se pretende interpretar; análise e destaque dos elementos do texto; busca por padrões nos textos analisados (semelhanças); agrupamento das palavras-chave.

\section{RESULTADOS E DISCUSSÃO}

Ao todo, o método acima detalhado permitiu a identificação de 50 artigos sobre accountability na Administração Pública, datando de 1997 até 2016, de acordo com a Figura1.

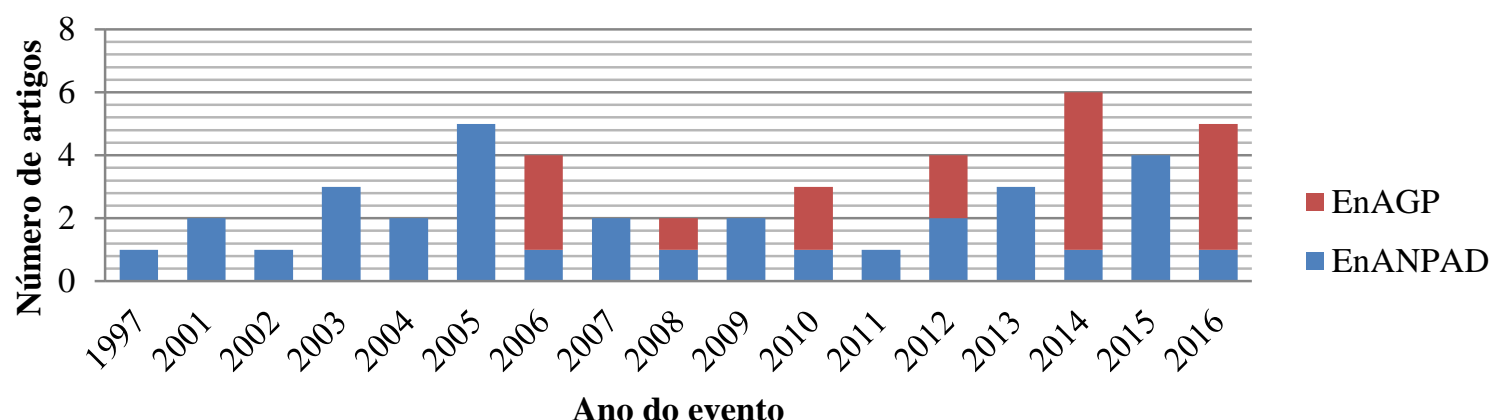

Figura 1. Evolução da publicação ao longo dos anos

Percebem-se três picos de publicações, em 2005 e 2016, com a apresentação de cinco artigos, e em 2014 com seis artigos. Nota-se que, nos anos em que os dois eventos ocorrem, há um maior número de artigos sobre o tema. Um fato positivo para a temática é que, em ambos os eventos, houve uma manutenção do número de trabalhos: no EnANPAD foram encontrados 1, 4, e 1 trabalhos nas edições a partir de 2014; já no EnAPG, a partir de 2012, foram encontrados 2, 5 e 4 trabalhos em suas edições. 
Os estudos relacionados indicam essa tendência de manutenção dos trabalhos, segundo Silveira e Silveira (2006), é bem perceptível a discussão da questão da accountability no Brasil e já há um bom número de textos tratando do assunto. Silva (2013) ressalta que os estudos sobre o tema pela academia no Brasil são bastante incipientes, assim, pode-se concluir que o tema accountability ainda tem espaço nas discussões sobre administração pública (DUARTE et al., 2016).

Por fim, nota-se que em 1997 houve a apresentação de um trabalho sobre o tema no EnANPAD, corroborando Rezende, Silva e Santos (2015) que destacam que a accountability já era tema de debate na agenda da reforma de 1995, como forma de melhorar tanto o controle e a participação nas políticas públicas quanto a legitimação do próprio governo. Apenas em 2001 foram apresentados outros trabalhos sobre o tema no evento.

Verificou-se que 69 autores são responsáveis pelos 50 artigos analisados. Desses autores, foi possível perceber que 14 participaram da elaboração de mais de um trabalho: sete autores colaboraram em dois artigos; três autores colaboram em três artigos; dois autores colaboraram em quatro artigos; um autor colaborou em cinco artigos; e um autor colaborou em seis artigos. Esses dados podem indicar que alguns autores deram continuidade nas pesquisas sobre o tema. Dos trabalhos publicados nos encontros, 22 (44\%) foram escritos por dois autores, 17 (34\%) por um único autor, 8 (16\%) por três autores e apenas $3(6 \%)$ por quatro autores.

Entre os objetos estudados nos artigos do do EnANPAD e EnAPG no contexto da accountability, conforme Tabela 1 destaca-se o caso dos portais governamentais estudados em sete artigos e o Tribunal de Contas estudado em cinco artigos. Além disso, foram objeto de estudo de três artigos as organizações da Sociedade Civil, um órgão Público Municipal não identificado e a Administração Pública brasileira; e foram objeto de estudo de dois artigos órgãos de controle não identificados, hospital universitário, agências reguladoras e os gastos públicos. Os demais objetos de estudo nos artigos apresentaram-se de maneira isolada. De acordo com a literatura analisada, os portais governamentais são elementos potencializadores da accountability, pois possibilitam uma prestação de contas do setor público à sociedade, bem como instalam um processo contínuo de interação entre as duas esferas (PINHO, 2006). Assim, dada a importância dos portais governamentais para a accountability, é fácil perceber o motivo de ser o objeto mais pesquisado nos artigos analisados. 
Tabela 1. Objetos de pesquisa nos quais a accountability foi analisada.

\begin{tabular}{lc}
\hline \multicolumn{1}{c}{ Objeto principal de pesquisa } & $\begin{array}{c}\text { Quantidade de } \\
\text { artigos }\end{array}$ \\
\hline Portais governamentais & 7 \\
Tribunal de Contas & 5 \\
Organizações da Sociedade Civil & 3 \\
Órgão Público municipal & 3 \\
Administração Pública Brasileira & 3 \\
Órgão de controle & 2 \\
Hospital Universitário Público & 2 \\
Agências Reguladoras & 2 \\
Gastos Públicosde & 2 \\
Controle & 2 \\
Programa Nacional de Fortalecimento da Agricultura Familiar & 1 \\
(PRONAF) & \\
Conselhos de Saúde & 1 \\
Universidade Federal & 1 \\
Lei da ficha limpa & 1 \\
Lei de Licitações & 1 \\
Lei de Responsabilidade Fiscal & 1 \\
Controladoria Geral da União & 1 \\
Ministério Público & 1 \\
Conselhos de Controle Social & 1 \\
Comissões Parlamentares & 1 \\
Comitê Municipal & 1 \\
Reforma Administrativa & 1 \\
Relação com os stakeholders & 1 \\
Tecnologias para accountability & 1 \\
Controle Social & 1 \\
Lavagem Dinheiro & 1 \\
Parcerias Públicas Privadas & 1 \\
Categorização accountability & 1 \\
Políticas Fiscais & 1 \\
\hline
\end{tabular}

Fonte. Elaborado a partir dos Anais do EnANPAD e EnAPG de 1997 a 2016.

Com relação aos principais elementos presentes nos conceitos de accountability apresentados nos artigos, conforme Tabela 2, observou-se que o termo "controle" foi o mais citado, aparecendo em 29 artigos. Os termos "Prestação de Contas", "Transparência" e "Responsabilidade" foram os segundos mais citados, totalizando 27 artigos, seguido dos termos "sanções" e "obrigação" (dezessete); "responsabilização" (dezesseis); "controle social" e " delegação" (quinze); "informação" (treze); "punição", "participação" e "responsividade" (doze).

Os resultados corroboram com a bibliografia, uma vez que, segundo Loureiro e Abrucio (2003), normalmente a literatura sobre accountability trata das discussões sobre transparência e responsabilização como forma de melhorar a eficiência da ação governamental e Matins e Tavares (2015) afirmam que as palavras "responsabilização" e "prestação de contas" são as mais citadas nas definições do termo accountability.

Pesquisar sobre os termos que formam o conceito de accountability é importante, visto que esse é um aspecto central na administração pública contemporânea e tem 
suscitado profundas discussões no campo da ciência política, talvez, por isso, o termo tem sido utilizado com diversos significados, conforme as interpretações e idiossincrasias dos estudiosos (SILVA; BELEM, 2005).

Tabela 2. Elementos considerados nos conceitos de accountability

\begin{tabular}{lc}
\hline \multicolumn{1}{c}{ Elementos considerados no conceito } & Quantidade de artigos \\
\hline Controle & 29 \\
Prestação de contas & 27 \\
Transparência & 27 \\
Responsabilidade & 27 \\
Sanções & 17 \\
Obrigação & 17 \\
Responsabilização & 16 \\
Controle social & 15 \\
Delegação & 15 \\
Informação & 13 \\
Avaliação retrospectiva & 12 \\
Punição & 12 \\
Participação & 12 \\
Eficiência & 8 \\
Responsividade & 4 \\
Supervisão & 4 \\
Ações das agências de controle & 4 \\
Justificação & 4 \\
Eficácia & 4 \\
Governança & 4 \\
Imputabilidade & 4 \\
Fiscalização & 4 \\
Controle eleitoral & 2 \\
Sociedade Civil & 2 \\
\hline
\end{tabular}

Fonte. Elaborado a partir dos Anais do EnANPAD e EnAPG de 1997 a 2016.

Do mesmo modo que existe uma variedade de entendimento sobre o conceito de accountability, sendo necessário decompor o conceito em elementos para que se possa entender melhor, também no que se refere às tipologias de accountability existe um conjunto grande de proposições, por isso faz-se uma tabela apresentando o foco das dimensões (tipologias) encontradas na pesquisa e a quantidade de artigos que as citaram.

Conforme Tabela 3, analisando os tipos de accountability apresentados pelos autores dos artigos analisados, constatou-se que a tipologia mais citada foi a “accountability vertical" e a "accountability horizontal” de O'Donnell (1998), sendo utilizada em 31 artigos. O resultado vai ao encontro do que Santos, Silva e Morais (2016) identificaram na sua pesquisa, que a maioria dos autores estudiosos da accountability utiliza a divisão clássica sugerida por O’Donnell. 
DOI 10.18605/2175-7275/cereus.v11n1p96-116
MAURICIO, N.M.M.; RODRIGUES, T.A.N.M; NUNES, S.G.C.

Accountability: uma revisão sistemática da produção do EnANPAD e EnAPG.

Tabela 3. Abordagens (tipologias) accountability.

\begin{tabular}{|c|c|c|c|}
\hline Autor & Abordagens (tipologias) & Foco & $\begin{array}{c}\text { Quantidade de } \\
\text { artigos }\end{array}$ \\
\hline O’Donnell (1998) & $\begin{array}{l}\text { Accountability vertical } \\
\text { Accountability horizontal }\end{array}$ & $\begin{array}{l}\text { Relação entre desiguais: quem } \\
\text { detém o poder e quem o } \\
\text { delega } \\
\text { Relação entre agências de } \\
\text { Estado com equilíbrio de poder }\end{array}$ & 31 \\
\hline Mainwaring (2003) & Accountability intraestado & $\begin{array}{l}\text { Relação entre agências de } \\
\text { Estado sem equilíbrio de poder }\end{array}$ & 4 \\
\hline Schmitter (2007) & Accountability oblíqua & $\begin{array}{l}\text { Tanto na relação principal- } \\
\text { agente como entre agências de } \\
\text { Estado }\end{array}$ & 2 \\
\hline Smulovitz e Peruzzotti (2003) & Accountability societal & $\begin{array}{l}\text { Movimento da sociedade civil e } \\
\text { da mídia, atuando como } \\
\text { principal na relação com a } \\
\text { autoridade pública }\end{array}$ & 2 \\
\hline Romzek (1996) & $\begin{array}{l}\text { Accountability hierárquica } \\
\text { Accountability legal } \\
\text { Accountability política } \\
\text { Accountability profissional }\end{array}$ & $\begin{array}{l}\text { Supervisão e relação entre } \\
\text { superior e subordinado } \\
\text { Cumprimento das leis e } \\
\text { obrigações } \\
\text { Orientação do serviço aos } \\
\text { clientes } \\
\text { Responsabilidade }\end{array}$ & 2 \\
\hline $\begin{array}{l}\text { Grant e } \\
\text { Keohane (2005) }\end{array}$ & $\begin{array}{l}\text { Accountability legal } \\
\text { Accountability de mercado } \\
\text { Accountability pelos pares } \\
\text { Accountability de reputação }\end{array}$ & $\begin{array}{l}\text { Relações entre superior e } \\
\text { subordinado dentro das } \\
\text { organizações } \\
\text { Relações entre os Estados e } \\
\text { os organismos multilaterais } \\
\text { Fiscalização de recursos } \\
\text { financeiros gerenciado pelos } \\
\text { organismos multilaterais } \\
\text { Cumprimento das normas } \\
\text { pelos organismos multilaterais } \\
\text { Relação entre investidores e } \\
\text { consumidores e o mercado } \\
\text { Relação entre organizações } \\
\text { homólogas } \\
\text { Reputação dos agentes }\end{array}$ & 2 \\
\hline Denhardt e Denhardt (2003) & $\begin{array}{l}\text { Accountability de processos } \\
\text { Accountability de resultados } \\
\text { Accountability democrática }\end{array}$ & $\begin{array}{l}\text { Conformidade às leis e às } \\
\text { normas procedimentais } \\
\text { Resultados } \\
\text { Conformidade às leis e às } \\
\text { normas procedimentais, nos } \\
\text { resultados e no "dever" do } \\
\text { servidor público }\end{array}$ & 1 \\
\hline $\begin{array}{l}\text { Quiñones, Herrera \& } \\
\text { Hernandes (2011) }\end{array}$ & Accountability transversal & $\begin{array}{l}\text { Movimento da sociedade civil e } \\
\text { da mídia, atuando como } \\
\text { principal na relação com a } \\
\text { autoridade pública }\end{array}$ & 1 \\
\hline Xavier (2014) & $\begin{array}{l}\text { Accountability Legal, } \\
\text { Horizontal e de Reputação } \\
\text { (Dimensão Constitucional) } \\
\text { Accountability de } \\
\text { Transparência, de } \\
\text { Participação e de Avaliação } \\
\text { (Dimensão Organizacional) }\end{array}$ & $\begin{array}{l}\text { Processos } \\
\text { Resultados }\end{array}$ & 1 \\
\hline
\end{tabular}

Fonte. Elaborado a partir dos Anais do EnANPAD e EnAPG de 1997 a 2016. 


\section{CONSIDERAÇÖES FINAIS}

Ao analisar a contribuição dos EnANPADs e EnAPGs no período de 1997 a 2016 para as pesquisas, as reflexões e as discussões sobre a accountability, percebe-se que o tema é extremamente complexo, multidisciplinar e multidimensional, dessa forma, não se deve falar em accountability como um conceito fechado. Os diversos artigos utilizam conceitos diferentes, em função do tema que se estuda, apropriam-se de diversas dimensões conceituais para delimitar o campo de análise da accountability.

Identificou-se 50 artigos sobre accountability nos EnANPADs e EnAPGs no período de 1997 até 2016. Houve três picos de publicações, em 2005 e 2016 com a apresentação de cinco artigos e em 2014 com seis artigos, além disso, constatou-se que houve uma manutenção do número de trabalhos sobre a temática.

A partir da literatura levantada na pesquisa, identificou-se que 69 autores são responsáveis pelos 50 artigos analisados; desses autores, foi possível perceber que 14 participaram na elaboração de mais de um trabalho, o que pode indicar que alguns autores deram continuidade nas pesquisas sobre o tema; e 22 artigos foram escritos por dois autores, 17 por um único autor, 8 por três autores e apenas 3 por quatro autores.

Quanto aos objetos estudados no contexto da accountability, destaca-se o caso dos portais governamentais estudados em sete artigos, e o Tribunal de Contas estudado em cinco artigos.

Analisando os principais elementos presentes nos conceitos de accountability apresentados nos artigos, observou-se que o termo "controle" foi o mais citado, aparecendo em 29 artigos, seguido dos termos "Prestação de Contas", "Transparência" e "Responsabilidade" citados por 27 artigos.

Com relação às dimensões (tipologias) de accountability apresentados pelos autores dos artigos analisados, constatou-se que a tipologia mais citada foi a "accountability vertical" e a "accountability horizontal" de O'Donnell (1998), sendo utilizada em 31 artigos.

É oportuno destacar que o tema accountability continuará a se tornar cada vez mais importante na Administração Pública, em busca da mitigação da corrupção, melhoria na governança e efetivação da democracia. Assim, não se buscou esgotar o tema, mas se espera que esta pesquisa sirva de base para futuros estudos, com métodos diferenciados que contribuam para o entendimento e ampliação da visão sobre o assunto apresentado. 


\section{REFERÉNCIAS}

BARDIN, L. Análise do conteúdo. Tradução de Luís Antero Reto e Augusto Pinheiro. São Paulo: Edições 70, 2016.

BORGES, T. J. G. Práticas de Accountability na Administração Pública Brasileira: existe espaço para este Instrumento na Saúde Pública Tupiniquim - via Conselhos de Saúde? In: ENCONTRO DA ANPAD, 38., 2014, Rio de Janeiro. Anais... . [s. L.]: Anpad, 2014. p. 1 $-17$.

CENEVIVA, R.; FARAH, M. F. S. Avaliação, informação e responsabilização no setor público. Revista de Administração Pública-RAP, v. 46, n. 4, p. 993-1016, 2012.

DENHARDT, J. V.; DENHARDT, R. B. The new public service: Serving not steering.Armonk: M. E. Sharpe, 2003.

DUARTE, A. L. F. et al., Deborah Moraes. Abordagens de Accountability no EnANPAD: Análise de Conteúdo dos Artigos da Divisão de Administração Pública. In: Encontro de Administração Pública e Governança, 7., 2016, São Paulo. Anais... . [s. L.]: EnAPG, 2016. p. 1 - 8.

GIL, A. C. Gestão de Pessoas: Enfoque nos Papéis Profissionais. 10 ed. 6 reimpr. São Paulo: Atlas, 2006.

GRANT, R. W.; KEOHANE, R. O. accountability and Abuses of Power in World Politics. The American Political Science Review, Vol. 99, №1, 2005, pp. 29-43 Published by: American Political Science Association Stable. Disponível em: <http://www.jstor.org/stable/30038917>.

JUANIHA, A. M.I; PEIXE, B. C. S. Impacto da Accountability Democrática nos Gastos Públicos em Educação para o Desenvolvimento: Uma Análise entre Países da América Latina. In: Encontro de Administração Pública e Governança, 7., 2016, São Paulo. Anais... . [s. L.]: EnAPG, 2016. p. 1 - 8.

KOPPELL, J. G. S. Pathologies of Accountability: ICANN and the Challenge of "Multiple Accountabilities Disorder". Public Administration Review, v. 65, n. 1, p. 94-108, jan./fev. 2005.

LIMA, R. C.; CAMPOS, E. S. Accountability: Uma Análise Comparativa entre o Poder Executivo e Judiciário sobre a Divulgação de dados e informações, em seus Sítios Eletrônicos. In: Encontro de Administração Pública e Governança, 4., 2010, Vitória. Anais... . [s. L.]: EnAPG, 2010. p. 1 - 17.

LOUREIRO, M. R.; ABRUCIO, F. L. Políticas Fiscais e Accountability: o Caso Brasileiro. In: ENCONTRO DA ANPAD, 27, 2003, Atibaia. Anais... . [s. L.]: Anpad, 2003. p. 1 - 16.

LOUZADA, S. V.; FONTES, J. R.; REZENDE, J. F. C. O uso da internet para promoção da accountability pelas empresas estatais federais brasileiras. In: Encontro de Administração Pública e Governança, 4., 2010, Vitória. Anais... . [s. L.]: EnAPG, 2010. p. 1 - 17.

MAINWARING, S.; WELNA, C. Democratic accountability in Latin America. 1.ed. Oxford: Oxford University Press, 2003. 
MARTINS, F. J. O.; TAVARES, T. M. T. C. Accountability na Administração Pública Brasileira: Fundamentos Teóricos e Componentes Constitutivos. In: ENCONTRO DA ANPAD, 39., 2015, Belo Horizonte. Anais... . [s. L.]: Anpad, 2015. p. 1 - 18.

MORAIS, L. S. Accountability suas interfaces na Administração Pública Brasileira: a visão do controle interno estadual. In: Encontro de Administração Pública e Governança, 6., 2014, Belo Horizonte. Anais... . [s. L.]: EnAPG, 2014. p. 1 - 15.

NASCIMENTO, D. C.; TEODÓSIO, A. S. S. Participação Popular na Accountability de Governos Locais: um estudo sobre a atuação do movimento Nossa Betim. In: ENCONTRO DA ANPAD, 39., 2015, Belo Horizonte. Anais... . [s. L.]: Anpad, 2015. p. 1 16.

O'DONNELL, G. (1998). Accountability horizontal e novas poliarquias. Revista Lua Nova, n. 44. São Paulo, p. 27-54.

SMULOVITZ, C.; PERUZZOTTI, E. 2003. Accountability social: la otra cara del control. In: Controlando la Política. Cidadanos y Medios em las Democracias Lationamericanas. Buenos Aires, Editorial Temas, 38 pp.

PINHO, J. A. G.; SACRAMENTO, A. R. S. (2009). Accountability: já podemos traduzi-la para o português? Revista da Administração Pública. Rio de Janeiro v.43, no.6, p.13431368.

PINHO, J. A. G. Accountability em Portais Estaduais e Municipais no Brasil: Realidades Distantes das Promessas. In: Encontro de Administração Pública e Governança, 2., 2006, São Paulo. Anais... . [s. L.]: EnAPG, 2006. p. 1 - 12.

PÓ, M. V. Desenho e Funcionamento dos Mecanismos de Controle e Accountability das Agências Reguladoras Brasileiras: Semelhanças, Diferenças e Idiossincrasias. In: ENCONTRO DA ANPAD, 29, 2005, Brasília. Anais... . [s. L.]: Anpad, 2005. p. 1 - 12.

QUIÑONES, A.H.; HERREA, J.F.; HERNANDEZ, E. B. 2011. Análisis y Estudio de Experiencias de Accountability Social en América Latina. CIDER-Centro de Estudios Interdisciplinarios Sobre el Desarrollo, 1-86.

REZENDE, M. M.; SILVA, W. A. C.; SANTOS, A. O. Accountability no Arranjo de Governança do Setor Público: estudo em uma universidade federal. In: ENCONTRO DA ANPAD, 39., 2015, Belo Horizonte. Anais.... [s. L.]: Anpad, 2015. p. 1 - 15.

RIBEIRO, J. F.; CAMPELO, S. M.; ARAÚJO, F. S. A. Os websites dos Tribunais de Contas como instrumentos de accountability: uma análise empírica das informações disponibilizadas. In: ENCONTRO DA ANPAD, 29, 2005, Brasília. Anais... . [s. L.]: Anpad, 2005. p. $1-16$.

ROCHA, A. C. Accountability na Administração Pública: a Atuação dos Tribunais de Contas. In: ENCONTRO DA ANPAD, 33., 2009, São Paulo. Anais... . [s. L.]: Anpad, 2009. p. $1-16$.

ROCHA, A. C. Accountability: Três Modelos Teóricos, Três Abordagens. In: ENCONTRO DA ANPAD, 34., 2010, Rio de Janeiro. Anais... . [s. L.]: Anpad, 2010. p. 1 - 15. 
ROCHA, A. C. Auditoria de Gestão - Uma Forma Eficaz de Promoção da Accountability. In: ENCONTRO DA ANPAD, 31, 2007, Rio de Janeiro. Anais... . [s. L.]: Anpad, 2007. p. 1 $-15$.

ROCHA, A. C. et al. A coprodução do controle como bem público essencial à accountability. In: ENCONTRO DA ANPAD, 36., 2012, Rio de Janeiro. Anais... . [s. L.]: Anpad, 2012. p. 1 - 16.

ROESCH, S. M. A. Projetos de Estágio em Administração: guia para estágios, trabalhos de conclusão, dissertação e estudos de caso. 3.ed. São Paulo: Atlas, 2005.

ROMZEK, B. Enhancing accountability. In: PERRY, J. L. (ed.). Handbook of public administration. 2. Ed. San Francisco: Jossey-Bass, 1996, p. 97 - 114.

SACRAMENTO, A. R. S.; PINHO, J. A. G. Corrupção e Accountability no Brasil: Um Olhar A Partir de Organizações da Sociedade Civil. In: ENCONTRO DA ANPAD, 36., 2012, Rio de Janeiro. Anais... . [s. L.]: Anpad, 2012. p. 1 - 16.

SACRAMENTO, A. R. S.; PINHO, J. A. G. Accountability Social e Lei da Ficha Limpa no Brasil: Um Estudo sobre as Eleições 2014. In: ENCONTRO DA ANPAD, 39., 2015, Belo Horizonte. Anais... . [s. L.]: Anpad, 2015. p. 1 - 16.

SANO, H.; ABRUCIO, F. L. Reforma do Estado, Organizações Sociais e Accountability: o caso paulista. In: ENCONTRO DA ANPAD, 27, 2003, Atibaia. Anais... . [s. L.]: Anpad, 2003. p. $1-16$.

SANTOS, R. O.; SILVA, W. A. C.; MORAIS, K. Estudo da Accountability Baseado nas Tipologias de Koppell: uma Análise em um Hospital Universitário. In: ENCONTRO DA ANPAD, 40., 2016, Costa do Sauípe. Anais... . [s. L.]: Anpad, 2016. p. 1 - 17.

SCHMITTER, P. C. Europe University Institute. 2007.

http://www.eui.eu/Documents/DepartmentsCentres/SPS/Profiles/Schmitter/PCSPoliticalAc countbilityJan07.pdf.

SILVA, F. A. C. S.; BELEM, A. C. S. Accountability e Políticas Públicas para o Controle da Lavagem de Dinheiro: Uma Abordagem Comparativa das Estratégias do Brasil e EUA. In: ENCONTRO DA ANPAD, 29, 2005, Brasília. Anais... . [s. L.]: Anpad, 2005. p. 1 - 17.

SILVA, W. A. C. et al. Análise da criação de valor econômico e Accountability em um Órgão Público. In: ENCONTRO DA ANPAD, 37., 2013, Rio de Janeiro. Anais... . [s. L.]: Anpad, 2013. p. 1 - 16.

SILVEIRA, J. S. T.; SILVEIRA, L. D. B. Desenvolvimento metodológico e aplicação de um índice de accountability aos municípios catarinenses. In: ENCONTRO DA ANPAD, 30, 2006, Salvador. Anais... . [s. L.]: Anpad, 2006. p. 1 - 14.

TRIBUNAL DE CONTAS DA UNIÃO - TCU. Referencial básico de governança aplicável a órgãos e entidades da administração pública. Brasília: TCU, 2014. v.2, 80p. 
VIEIRA, L. H. S.; PEREIRA, Maria Cecília Gomes. Mecanismos de Accountability na Implementação do PRONAF. In: ENCONTRO DA ANPAD, 37., 2013, Rio de Janeiro. Anais... . [s. L.]: Anpad, 2013. p. 1 - 16.

XAVIER, R. S. Accountability e regime de não proliferação nuclear: uma avaliação do modelo de Vigilância Mútua Brasileiro-Argentina de Salvaguardas Nucleares. 2014, $199 \mathrm{f}$. v.1. Tese (Doutorado) - UFRJ. Instituto de Economia. Pós-Graduação em Políticas Públicas, Estratégia e Desenvolvimento. Rio de Janeiro, 2014.

XAVIER, R. S. Accountability e as suas Múltiplas Abordagens: um Balanço Teórico. In: ENCONTRO DA ANPAD, 35., 2011, Rio de Janeiro. Anais... . [s. L.]: Anpad, 2011. p. 1 14.

ZAPELINI, M. B. Accountability na gestão de recursos hídricos: o comitê Itajaí como instrumento de sua ampliação. In: Encontro de Administração Pública e Governança, 5., 2012, Salvador. Anais... . [s. L.]: EnAPG, 2012. p. 1 - 16. 